\title{
Striatal Input- and Rate-Dependent Effects of Muscarinic Receptors on Pallidal Firing
}

\author{
Enrique Querejeta, ${ }^{1}$ Alberto Alatorre, ${ }^{1}$ Alain Ríos, ${ }^{1}$ Rafael Barrientos, ${ }^{1}$ \\ Aldo Oviedo-Chávez, ${ }^{1}$ Rosa Amalia Bobadilla-Lugo, ${ }^{1}$ and Alfonso Delgado \\ ${ }^{1}$ Sección de Estudios de Posgrado e Investigación, Escuela Superior de Medicina, Instituto Politécnico Nacional, \\ Plan de San Luis y Díaz Mirón, 11340 México, DF, Mexico \\ ${ }^{2}$ Departamento de Fisiología, Facultad de Medicina Universidad Autónoma de Chihuahua, Circuito Universitario Campus II, \\ 31125 Chihuahua, Chih, Mexico
}

Correspondence should be addressed to Enrique Querejeta, equerejeta@ipn.mx

Received 13 October 2011; Accepted 24 November 2011

Academic Editors: N. Berretta, C. Capurso, and E. Kumamoto

Copyright ( 2012 Enrique Querejeta et al. This is an open access article distributed under the Creative Commons Attribution License, which permits unrestricted use, distribution, and reproduction in any medium, provided the original work is properly cited.

The globus pallidus (GP) plays a key role in the overall basal ganglia (BG) activity. Despite evidence of cholinergic inputs to GP, their role in the spiking activity of GP neurons has not received attention. We examine the effect of local activation and blockade of muscarinic receptors (MRs) in the spontaneous firing of GP neurons both in normal and ipsilateral striatum-lesioned rats. We found that activation of MRs produces heterogeneous responses in both normal and ipsilateral striatum-lesioned rats: in normal rats the response evoked by MRs depends on the predrug basal firing rate; the inhibition evoked by MRs is higher in normal rats than in striatum-lesioned rats; the number of neurons that undergo inhibition is lower in striatum-lesioned rats than in normal rats. Our data suggest that modulation of MRs in the GP depends on the firing rate before their activation and on the integrity of the striato-pallidal pathway.

\section{Introduction}

The use of antimuscarinic drugs in the management of Parkinson's disease either as monotherapy or as an adjunct to other drugs is still in wide practice $[1,2]$. The initial concepts of BG function have pointed out to the striatum as the target of antimuscarinic drugs to relief Parkinsonian motor symptoms $[3,4]$. However, the presence of MRs modifies the activity of other BG nuclei [5-7].

The GP plays a key role in the global activity of basal ganglia [8]. Variations in the basal spontaneous firing rate of pallidal neurons are related to movement disorders both in humans and in animal models of Parkinson's disease $[9,10]$. The effect of a wide variety of neurotransmitters on the electrical activity of GP neurons has been studied [1116], yet, despite the presence of cholinergic fibers in the GP coming from the pedunculopontine nucleus (PPN) [17-20], there are no studies on the effect of acetylcholine on the spiking activity of GP neurons.
Previous works have shown the presence of MRs in the GP $[21,22]$ but studies of in situ hybridization and single-cell reverse transcription-polymerase chain reaction techniques have not detected mRNA for MRs in GP neurons. In addition, mRNA for M1 and M4 receptors has been found in medium spiny striatal neurons [23-25] projecting to the GP. In this context, Kayadjanian et al. [26] demonstrated that activation of MRs increases GABA release in GP rat brain slices and that this effect could be blocked by a muscarinic antagonist. These data pointed us to examine the regulation of GABA release in the GP by presynaptic striato-pallidal MRs. Therefore, here we analyze the effect of the local activation and blockade of MRs on the spontaneous spiking rate of GP neurons in both normal and ipsilateral striatumlesioned rats.

\section{Material and Methods}

Experiments were performed on male Wistar rats weighing $180-220 \mathrm{~g}$. Rats were maintained and handled according 
to the guidelines of the ESM-IPN Animal Care and Use Committee and followed the Guide for the Care and Use of Laboratory Animals published by the U.S. National Institutes of Health.

2.1. Surgery and Drug Application. Rats were anaesthetized with chloral hydrate $(300 \mathrm{mg} / \mathrm{kg}$, i.p.; supplemented as needed) and positioned in a stereotaxic apparatus. A heating pad and rectal thermometer system was employed to maintain body temperature at $36-38^{\circ} \mathrm{C}$. A $4 \mathrm{~mm}$ burr hole was drilled in the skull to allow for the stereotactical guide of glass electrodes and a steel double cannula system (30-gauge syringe needles) into the right GP. Tips of both cannulas were separated $0.1 \mathrm{~mm}$. The recording electrodes were placed $0.2 \mathrm{~mm}$ posterior to bregma, $3.0-3.3 \mathrm{~mm}$ lateral, and 4$6 \mathrm{~mm}$ ventral to brain surface according to the atlas of Paxinos and Watson [27]. The injection cannulas were placed at an angle of $70^{\circ}$ in the latero-medial direction to the following coordinates: $1.1 \mathrm{~mm}$ posterior to bregma, $5.7 \mathrm{~mm}$ lateral, $5.6 \mathrm{~mm}$ ventral to the brain surface. Bethanechol and oxotremorine were used as muscarinic agonists. Atropine was employed as muscarinic antagonist. Tacrine, a selective acetylcholinesterase inhibitor, was locally applied to disclose any tonic cholinergic input to the GP. All drugs were purchased from Sigma-Aldrich, USA; drugs were dissolved in saline $0.9 \%$ and infused into the GP using a $1 \mu \mathrm{L}$ syringe. The piston of the syringe was connected to a precision micrometer that allowed an infusion rate of $50 \mathrm{~nL} / 15 \mathrm{~s}$. The total volume injected per individual drug infusion was $100 \mathrm{~nL}$. Only neurons with five minutes of stable baseline firing were chosen for drug application. For any individual neuron, a $20 \%$ change of the baseline firing rate during the minute following drug infusion was considered significant [28]. The tips of the recording microelectrode and injection cannula were within a range of not greater than $0.2 \mathrm{~mm}$ [14].

2.2. Data Acquisition and Analysis. Standard extracellular recordings were made using glass electrodes $(2-6 \mathrm{M} \Omega$ ) filled with $2 \mathrm{M} \mathrm{NaCl}$ solution containing $2 \%$ pontamine sky blue dye. Extracellular signals were amplified 10,000 X, bandpass filtered between 0.3 and $3 \mathrm{kHz}$ (DAM-80 amplifier; WPI Saratosa, Fla, USA) and stored on an audiocassette device. Single-unit activity was isolated using a window discriminator WPI-121 (WPI Saratosa, Fla, USA). Spike times were preprocessed online and further analyzed offline using the INF-386 program for spike data analysis [29]. Statistical comparisons between or among groups were determined with Student's $t$-test and one-way ANOVA (with NewmanKeuls post-hoc test) using Prism 3 (GraphPad Software). Data are expressed as the mean \pm standard error or as a percentage of the control value (baseline activity).

2.3. Histology. At the end of each recording session, the level of the studied unit was marked by ejecting pontamine sky blue from the electrode by passing a $10 \mu \mathrm{A}$ negative constant current for 20 minutes. After experiments, rats were given a lethal overdose of pentobarbital and transcardiacally perfused with $4 \%$ formaldehyde. Following overnight incubation in formaldehyde, the brains were sliced ( $20 \mu \mathrm{m}$ thick slices) to verify the positions of the recording electrode and the injection cannulas. When either the recording electrode or the injection cannulas were not positioned within the GP, the experiment was discarded.

2.4. Striatal Lesions. Unilateral stereotaxic lesions of the corpus striatum were made in male Wistar rats (160-170 g, body weight) anaesthetized with chloral hydrate $(300 \mathrm{mg} / \mathrm{kg}$, i.p.). A $2 \mathrm{~mm}$ burr hole was drilled in the skull to allow for the stereotactical guide of a 30-gauge cannula into the striatum. The stereotaxic coordinates to the striatum were $1.3 \mathrm{~mm}$ anterior to bregma, $3 \mathrm{~mm}$ lateral to midline, and $4.8 \mathrm{~mm}$ ventral to dura [27]. The injection cannula was connected to a manual $5 \mu \mathrm{L}$ Hamilton syringe through a polyethylene plastic tube. A total of $1 \mu \mathrm{L}(120 \mathrm{nmol})$ of quinolinic acid was infused over $4 \mathrm{~min}$. At the end of the manual infusion, the cannula was left in place for 5 more minutes to improve solution delivery. Quinolinic acid was first dissolved in $4 \mathrm{M}$ $\mathrm{NaOH}$ and subsequently titrated with $1 \mathrm{~N} \mathrm{HCl}$ to $\mathrm{pH}$ 7.4. A sham group of rats was prepared using the same procedure.

2.5. Behavioral Testing. To evaluate the lesions, rats were tested for lesion-induced turning behavior with systemic application of apomorphine $(0.5 \mathrm{mg} / \mathrm{kg}$, i.p.) 10 days after the quinolinic acid lesion. The number of ipsilateral turns was recorded and only rats showing more than 20 wholebody turns/10 minutes were considered successfully lesioned and further used for ipsilateral GP extracellular recordings. The sham group of rats was also challenged with the same dose of apomorphine. In both successfully lesioned and sham rats, extracellular recordings of ipsilateral GP neurons were made 7 days after turning behavior analysis. Single-unit extracellular recordings were made as previously described in this work. At the end of each experiment, rats were given a lethal overdose of pentobarbital and transcardiacally perfused with $4 \%$ formaldehyde. The brains were then removed and left for overnight incubation. Thereafter, the brains were sliced ( $20 \mu \mathrm{m}$ thick slices) to evaluate the striatal lesion as a function of the right lateral ventricle area as well as to properly determine the recording sites and drug injection cannula trajectories. When either the recording electrode or the injection cannula was not positioned within the GP, the experiment was discarded.

\section{Results}

All the spikes recorded in this study belong to type II neurons (biphasic positive/negative waveforms [28]). The spontaneous firing rate of 97 neurons recorded from normal rats ranged from 6.3 to 98.7 spikes/s. The average spiking rate was $27.3 \pm 2.64$ spikes/s.

\subsection{Effect of Local Activation of MRs on the Baseline Spiking} Rate. To analyze the effect of the activation of MRs on the spiking rate of GP neurons in normal rats, we locally applied different doses of bethanechol, a muscarinic agonist. All doses of bethanechol produced heterogeneous effects (Table 1). Twenty neurons were recorded in the presence of 
TABLE 1: Response of GP neurons to different concentrations of bethanechol.

\begin{tabular}{lcccc}
\hline & Increase & Decrease & No response & Total \\
\hline $100 \mathrm{pmol}$ & $11(55 \%)$ & $7(35 \%)$ & $2(10 \%)$ & $20(100 \%)$ \\
$1 \mathrm{nmol}$ & $14(64 \%)$ & $6(27 \%)$ & $2(9 \%)$ & $22(100 \%)$ \\
$10 \mathrm{nmol}$ & $13(54 \%)$ & $7(29 \%)$ & $4(17 \%)$ & $24(100 \%)$ \\
\hline
\end{tabular}

Values represent $n(\%)$.

100 pmol bethanechol, 11 (55\%) increased their firing rate by $51.44 \pm 3.27 \%, 7(35 \%)$ diminished their firing rate by $46.05 \pm 5.7 \%$ and the remaining two neurons did not respond.

Application of $1 \mathrm{nmol}$ bethanechol increased the spiking rate by $94.96 \pm 25.78 \%$ in 14 out of 22 neurons (64\%). Six out of 22 neurons ( $27 \%$ ) showed a $67.39 \pm 11.37 \%$ inhibition in their firing rate, and the remaining two neurons (9\%) did not respond (Figures $1(\mathrm{~b})$ and $1(\mathrm{~d})$ ).

When we applied an infusion of $10 \mathrm{nmol}$ bethanechol to a group of 24 neurons, 13 (54\%) increased their firing rate by $223.47 \pm 20.8 \%$, seven $(29 \%)$ decreased their firing rate by $79.45 \pm 5.5 \%$, and four $(17 \%)$ did not respond.

The excitatory effect evoked by bethanechol was dosedependent. $10 \mathrm{nmol}$ bethanechol caused significant differences in the firing rate when compared to $100 \mathrm{pmol}$ and $1 \mathrm{nmol}(P<0.05$; one-way ANOVA post-hoc test; Figure $1(\mathrm{a}))$. In addition, the inhibitory effect of bethanechol was also dose-dependent. $10 \mathrm{nmol}$ bethanechol was statistically different compared to $100 \mathrm{pmol}(P<0.05$; one-way ANOVA post-hoc test; Figure 1(c)).

A detailed analysis of the firing rate before and after local infusion of $1 \mathrm{nmol}$ bethanechol revealed that neurons that were inhibited had a higher baseline firing rate compared to neurons that were excited or did not respond to bethanechol (Figure 2). In the six neurons that were inhibited by $1 \mathrm{nmol}$ bethanechol, their baseline firing rate was $49.51 \pm 7.33$ spikes/s. In contrast, the baseline spiking rate in neurons that were excited by $(n=14)$ or did not respond to $(n=2)$ the same concentration of bethanechol was $23.05 \pm 5.12$ and $17.86 \pm 1.48$ spikes/s, respectively.

The baseline firing rate in neurons that were inhibited by $1 \mathrm{nmol}$ bethanechol was statistically different when compared to the baseline firing rate of neurons that were excited $(P<0.01 ; t$-test $)$. Similarly, in the seven neurons that were inhibited by $10 \mathrm{nmol}$ bethanechol, the baseline firing rate $(54.72 \pm 4.33$ spikes/s) was higher when compared to the values of neurons that were exited $(20.14 \pm 5.49$ spikes/s; $P<0.01, t$-test). There was no statistically significant difference between the baseline firing rate of neurons that were inhibited and those that did not respond to $10 \mathrm{nmol}$ bethanechol.

\subsection{Effect of Local Blockade of MRs on the Baseline Spiking} Rate. The effect of the local infusion of $1 \mathrm{nmol}$ atropine, an unspecific muscarinic antagonist, was tested in 21 neurons. In 6 out of 21 (33\%) neurons, atropine increased the spontaneous firing rate by $163.69 \pm 85.5 \%$, in this group of neurons, the spontaneous firing rate previous to the application of the antagonist was $27.6 \pm 11.32$ spikes/s. In eight out of 21 neurons (38\%) atropine did not produce significant changes $(-4.25 \pm 5.09 \%)$. In neurons that did not respond to atropine, the baseline firing rate was $21.68 \pm 5.18$ spikes/s. In seven out of 21 neurons (33\%), local infusion of atropine diminished their baseline firing rate by $48.19 \pm 10.72 \%$, the baseline firing rate of this group of neurons before local application of atropine was $50.97 \pm 15.71$ spikes/s. There was not statistically significant difference between the baseline firing rate of those neurons that were inhibited and those that did not respond or were excited by atropine (one-way ANOVA post-hoc test; Figure 3(b)). In some neurons, the firing rate changes evoked by bethanechol were blocked by atropine (Figure 3(a)).

3.3. Effect of Local Blockade of Acetylcholinesterase on the Baseline Spiking Rate. To determine if there is a tonic release of acetylcholine in the GP, we locally applied tacrine, a selective inhibitor of acetylcholinesterase. Tacrine $(5 \mathrm{nmol})$ evoked heterogeneous responses in the firing rate of $10 \mathrm{GP}$ neurons: two $(20 \%)$ were excited by $58.9 \pm 24.42 \%$, four (40\%) were inhibited by $67.38 \pm 17.27 \%$, and the remaining four neurons (40\%) did not respond. The baseline spiking rate in neurons that were inhibited by tacrine was $37.24 \pm$ 7.17 spikes/s, while the baseline firing rate in neurons that were excited or did not respond was $19.85 \pm 0.21$ and $20.32 \pm$ $0.57 \mathrm{spikes} / \mathrm{s}$, respectively. There were statistically significant differences between the baseline firing rate of neurons that were inhibited and those that were exited or did not respond to tacrine $(P<0.01 ; t$-test; Figure 4$)$.

3.4. Effect of Local Activation of MRs by Bethanechol in Rats with Ipsilaterally Denervated Striatum. To analyze the contribution of the striato-pallidal pathway on the local responses evoked by MRs activation, we proceeded to destroy the ipsilateral striatum with quinolic acid. To test if the ipsilateral striatum was properly destroyed, we analyzed the rotational behavior by applying apomorphine $0.5 \mathrm{mg} / \mathrm{kg}$ (i.p.) one week after the infusion of the neurotoxic.

Rats that presented 20 whole-body turns/10 minutes were chosen to analyze the spiking activity of GP neurons. A sham group of four rats was prepared applying the same volume of saline.

We recorded GP neurons in the ipsilaterally denervated striatum five days after the rotational behavior test (Figure 5(a)). The mean baseline firing rate of 28 neurons recorded in lesioned rats was $22.33 \pm 2.1$ spikes/s (range: 5.2768.6 spikes/s). The local infusion of $1 \mathrm{nmol}$ bethanechol produced heterogeneous effects in GP neurons of lesioned rats (Table 2). In 19 out of 28 (68\%) neurons recorded from seven lesioned rats, bethanechol increased the firing rate by $102 \pm 27 \%$, and only in four $(14 \%)$ neurons bethanechol diminished the firing rate by $27.8 \pm 3.36 \%$. In the remaining five neurons $(18 \%)$ bethanechol had no effect. Further, 19 neurons were recorded in the sham group. Eleven out of 19 (58\%) were excited $87.2 \pm 17.3 \%$ by the same dose of bethanechol used in lesioned rats. Five out of 19 neurons (26\%) diminished the basal firing rate by $55.3 \pm 9.1 \%$. 


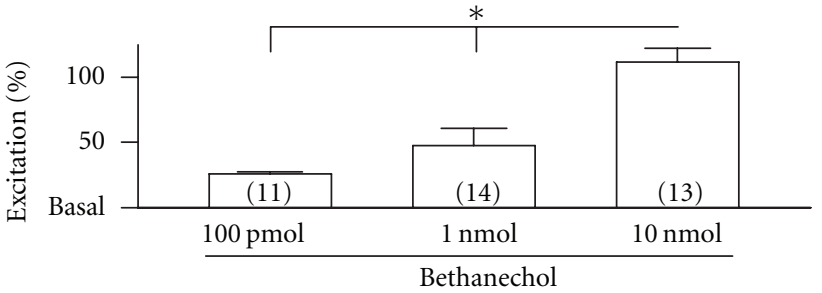

(a)

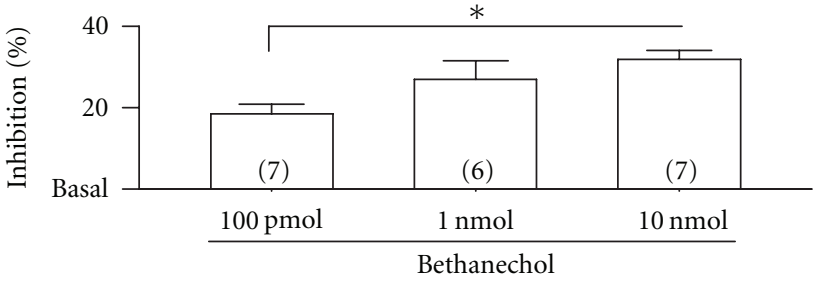

(c)

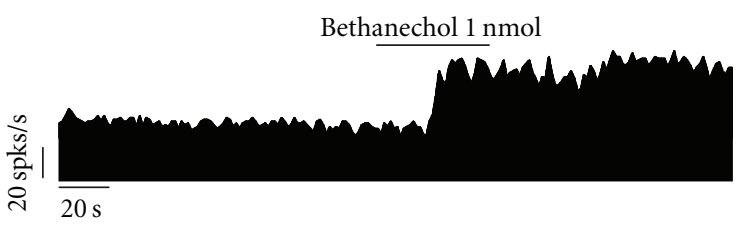

(b)

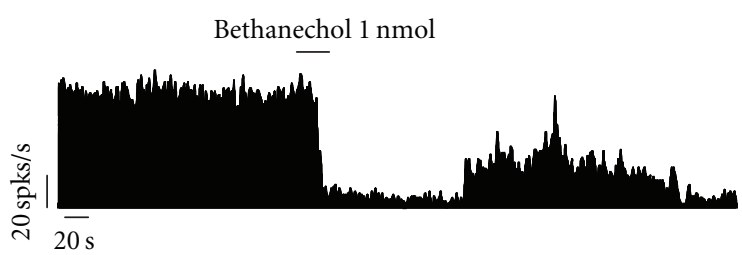

(d)

FIGURE 1: Intrapallidal activation of MRs produces heterogeneous effects on the baseline firing rate of globus pallidus neurons recorded in normal rats. (a) Bethanechol $100 \mathrm{pmol}, 1$ and $10 \mathrm{nmol}$ increases the spiking rate in a dose-dependent manner $\left({ }^{*} P<0.05\right.$ as compared to bethanechol $100 \mathrm{pmol}$ and $1 \mathrm{nmol}$. One-way ANOVA, Newman-Keuls post-hoc test). (b) Frequency histogram showing the increase in baseline firing rate induced by local application of $1 \mathrm{nmol}$ bethanechol. (c) In another group of globus pallidus neurons, bethanechol decreases the spiking rate in a dose-dependent manner. $\left({ }^{*} P<0.01\right.$, as compared to 100 pmol bethanechol, one-way ANOVA, NewmanKeuls post-hoc test). (d) Frequency histogram illustrating the inhibitory effect of $1 \mathrm{nmol}$ bethanechol on a pallidal neuron. spks/s, spikes per second.

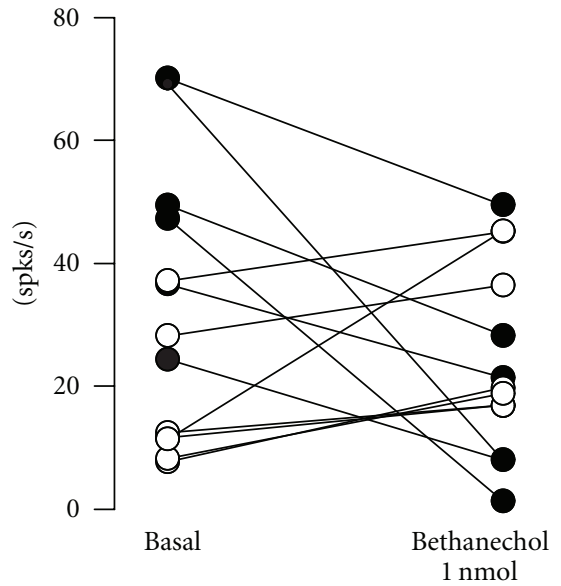

(a)

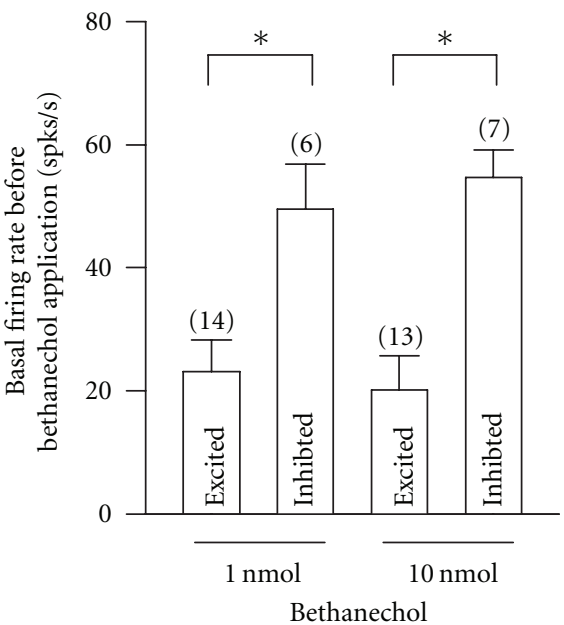

(b)

FIGURE 2: The effect of local activation of MRs depends on the firing rate before the application of different doses of bethanechol. (a) Shows that bethanechol $1 \mathrm{nmol}$ produces heterogeneous effects on the spiking rate of globus pallidus neurons depending on the baseline firing rate before drug application. Only data from six neurons that suffered excitation are plotted. (b) Statistics showing that the excitation or inhibition evoked by 1 and $10 \mathrm{nmol}$ bethanechol depends on the predrug baseline firing rate. ${ }^{*} P<0.01$; $t$-test. spks/s, spikes per second.

The remaining tree neurons $(16 \%)$ did not respond to bethanechol.

In neurons recorded from lesioned rats, the baseline firing rate of those cells that were inhibited by $1 \mathrm{nmol}$ bethanecol was $22.54 \pm 9.27$ spikes/s whereas in those that were excited by and in those that did not respond to bethanechol was $20.8 \pm 3.9$ and $22.15 \pm 3.22$ spikes/s, respectively. There were no statistically significant differences in the baseline firing rate of neurons recorded from lesioned rats independently of the effect of bethanechol. In the sham group of rats, the baseline spiking rate of the neurons that were inhibited was $48.2 \pm 6$ spikes/s, whereas in those neurons that were excited or did not respond, the baseline firing rate was $24 \pm 5.3$ and $21.5 \pm 3.7$ spikes/s.

3.5. Differences in the Response to the Activation of MRs in Sham and Lesioned Striatum. In sham rats, the baseline firing rate was higher in neurons that were inhibited by $1 \mathrm{nmol}$ 


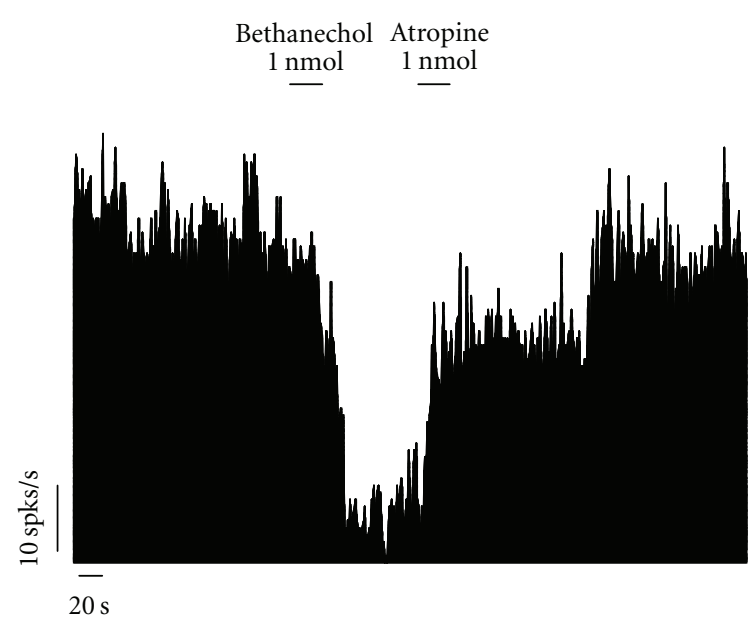

(a)

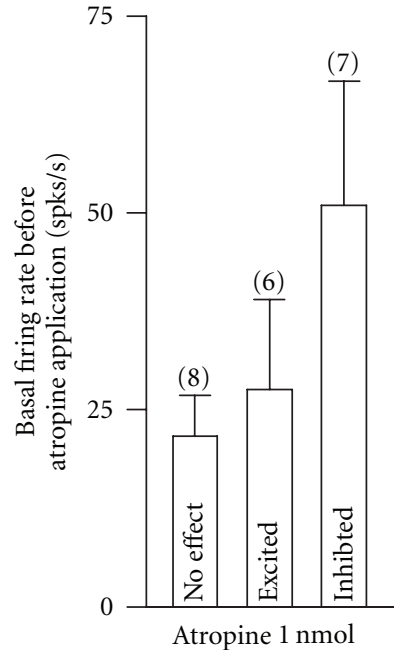

(b)

FIGURE 3: The heterogeneous effects in the spiking rate of globus pallidus neurons evoked by local blockade of MRs do not depend on the firing rate before application of atropine. (a) Frequency histogram of a pallidal neuron showing the blockade of the inhibition evoked by activation of MRs by atropine. spks/s, spikes per second. (b) Statistics illustrating that the effect of the local blockade of MRs in the spiking rate does not depend on the baseline firing rate before local infusion of $1 \mathrm{nmol}$ atropine.

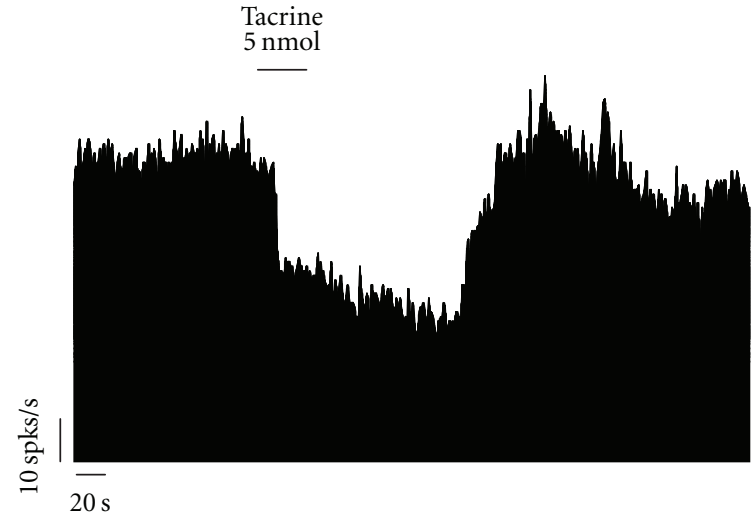

(a)

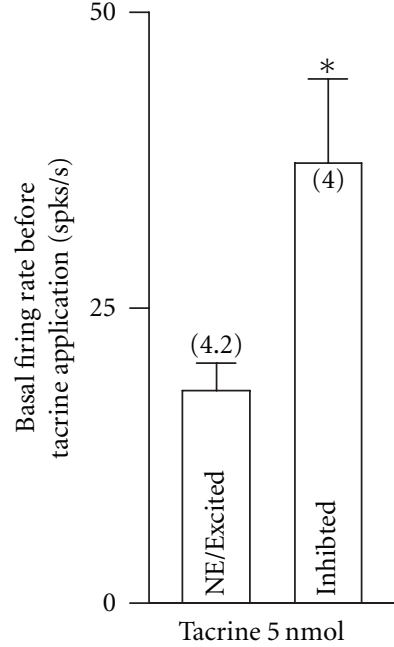

(b)

FIgURE 4: The increase in the tonic cholinergic input modifies the firing rate in globus pallidus neurons depending on the baseline firing rate before application of tacrine. (a) Frequency histogram showing the firing rate inhibition induced by local application of $5 \mathrm{nmol}$ tacrine in a globus pallidus neuron firing at $\sim 75$ spikes/s. (b) Statistics illustrating that the effect of the local blockade of acetylcholinesterase in the spiking rate depends on the baseline firing rate before local infusion of $5 \mathrm{nmol}$ tacrine $\left({ }^{*} P<0.01\right.$; $t$-test $)$. spks/s, spikes per second; NE/Excited, no effect or excitation.

bethanechol than in neurons of lesioned rats that were also inhibited $(P<0.01, t$-test; Figure 5(b)). The percent of inhibition evoked by $1 \mathrm{nmol}$ bethanechol in neurons recorded in sham rats was higher than the percent of inhibition in lesioned rats $(P<0.01, t$-test; Figure $5(c))$. There was no significant difference in the excitation induced by $1 \mathrm{nmol}$ bethanechol in both groups of rats. The percentage of neurons that were inhibited by the same dose of bethanechol was lower when compared to sham rats.
3.6. Effect of Oxotremorine on the Spiking Rate of GP Neurons of Sham and Ipsilaterally Denervated Striatum Rats. Finally, we analyzed the effect of another muscarinic agonist on the spontaneous firing rate of GP neurons in both sham and lesioned rats. We employed oxotremorine because the affinities of bethanechol and oxotremorine for M1 and M4 receptors are similar [30]. The baseline firing in sham rats and lesioned rats were $23.6 \pm 8.3$ and $25.9 \pm 1.8$ spikes/s, respectively. Oxotremorine $(1 \mathrm{nmol})$ produced heterogeneous 


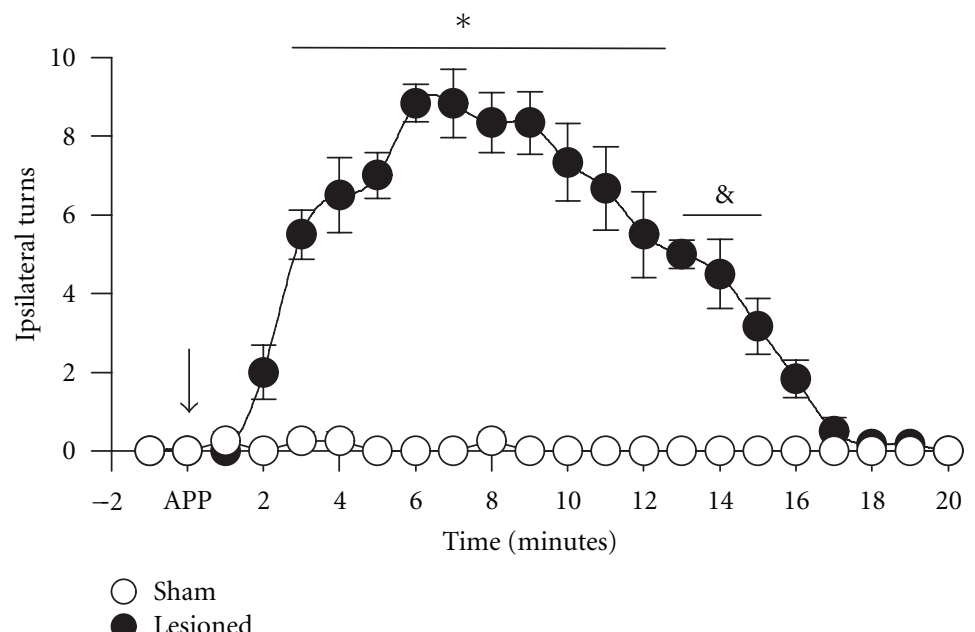

(a)

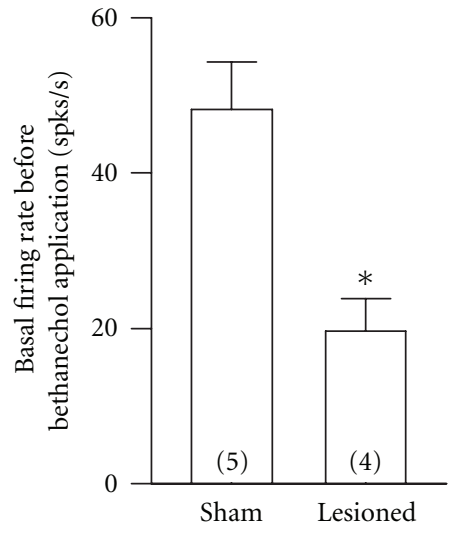

(b)

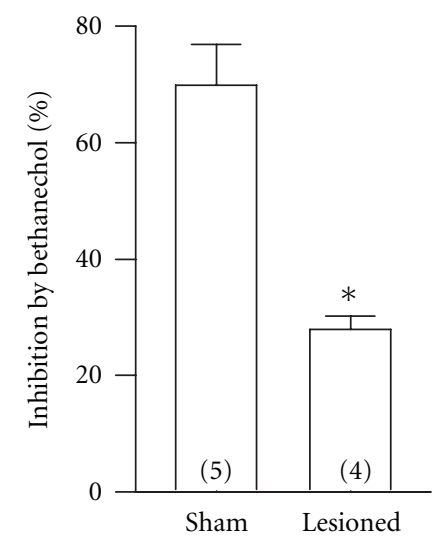

(c)

FIGURE 5: The activation of MRs in the globus pallidus has differential characteristics between sham and ipsilateral striatum-lesioned rats. (a) Intraperitoneal application of apomorphine $(0.5 \mathrm{mg} / \mathrm{kg})$ induces ipsilateral turning behavior in rats with striatal lesion. $\left({ }^{*} P<0.01\right.$; $\& P<0.05, t$-test). (b) In sham rats, the predrug $(1 \mathrm{nmol}$ bethanechol) baseline firing rate was higher in neurons that were inhibited by bethanecol than the baseline firing rate recorded in neurons from lesioned rats that were also inhibited by the same concentration of bethanechol ( ${ }^{*} P<0.029, t$-test). (c) The percent of inhibition evoked by $1 \mathrm{nmol}$ bethanechol is higher in neurons recorded in sham rats than in those recorded in lesioned rats $\left({ }^{*} P<0.04, t\right.$-test). APP, application time (down arrow); spks/s, spikes per second.

effects in sham rats: in seven out of 13 neurons $(54 \%)$ induced a $64.49 \pm 27 \%$ increase and two neurons $(16 \%)$ did not respond. In neurons that increased their firing and in neurons that did not respond, the baseline firing rate was $27 \pm 3.1$ and $22.45 \pm 2.3$ spikes/s, respectively. In four neurons $(30 \%)$ the firing rate diminished by $33 \pm 3.4 \%$. The spontaneous baseline firing rate in neurons that diminished their firing was $42.73 \pm 15.4$ spikes/s. Whereas in lesioned rats, the same dose of oxotremorine produced a $92 \pm 12.7 \%$ increase in the baseline firing rate of seven out of 11 neurons tested $(64 \%)$. In two out of 11 neurons $(18 \%)$ oxotremorine diminished the firing rate by $30.5 \pm 2.2 \%$. In the remaining two neurons (18\%) oxotremorine had no effect. There was a significant difference in the inhibition induced by $1 \mathrm{nmol}$ oxotremorine in both groups of rats $(P<0.01, t$-test, Table 3).

\section{Discussion}

Previous works have demonstrated that the GP is innervated by cholinergic pathways coming from the PPN $[17,18,20]$, a few pallidal neurons that express choline acetyltransferase together with glutamic acid decarboxylase that weights $67 \mathrm{kDa}$ (GAD67) [31], and the presence of MRs in the GP $[21,22]$ but there are few studies in which the functional role of the MRs in GP has been analyzed. Moreover, previous works have found mRNA for M1 and M4 receptors in medium spiny striatal neurons and the expression of M1 and M4 muscarinic receptor proteins in the striatum but have not detected mRNA for MRs in GP neurons [23-25, 32, 33]. This is the first study where the contribution of MRs to the spiking activity of GP neurons recorded in vivo both in normal and ipsilateral striatum-lesioned rats is analyzed. 
TABLE 2: Response of GP neurons to $1 \mathrm{nmol}$ bethanechol in normal and ipsilateral striatum-lesioned rats.

\begin{tabular}{lcccc}
\hline & Increase & Decrease & No response & Total \\
\hline Normal & $11(58 \%)$ & $5(26 \%)$ & $3(16 \%)$ & $19(100 \%)$ \\
Lesioned & $19(68 \%)$ & $4(14 \%)$ & $5(18 \%)$ & $28(100 \%)$ \\
\hline
\end{tabular}

Values represent $n(\%)$.

TABLE 3: Response of GP neurons to $1 \mathrm{nmol}$ oxotremorine in normal and ipsilateral striatum-lesioned rats.

\begin{tabular}{lcccc}
\hline & Increase & Decrease & No response & Total \\
\hline Normal & $7(54 \%)$ & $4(30 \%)$ & $2(16 \%)$ & $13(100 \%)$ \\
Lesioned & $7(64 \%)$ & $2(18 \%)$ & $2(18 \%)$ & $11(100 \%)$ \\
\hline
\end{tabular}

Values represent $n(\%)$.

Our results indicate that local activation or blockade of MRs produces heterogeneous effects in the spontaneous spiking activity of GP neurons of both groups of rats. In the one hand, in normal rats, the response of pallidal neurons evoked by activation of MRs depends on the baseline firing rate before local application of drugs; neurons with high baseline spiking rates diminish their activity, whereas those with lower spiking rates increase their activity or do not change. In the other hand, in pallidal neurons recorded from ipsilateral striatum-lesioned rats, we did not find any relationship between the basal firing rate before and after activation of MRs.

We demonstrate the presence of a tonic release of acetylcholine in the GP linked to the activity of MRs since if we block MRs with atropine or inhibit acetylcholinesterase, the spontaneous spiking rate significantly changes in most of the recording neurons.

Kayadjanian et al. [26] reported that in rat brain slices the application of a muscarinic agonist increases GABA release in the GP through phosphoinositides and that the effect is blocked by a muscarinic antagonist. These results were attributed to the activation of presynaptic MRs in the striato-pallidal pathway; however, there is not a direct demonstration of the presence of these receptors in pallidal terminals of medium spiny neurons. In this context, the activation of striatal M1 receptors diminishes a variety of calcium conductances including $\mathrm{N}$ and $\mathrm{P} / \mathrm{Q}$ currents in the dendrites and soma of medium spiny neurons [34]. $\mathrm{N}$ and $\mathrm{P} / \mathrm{Q}$ currents are associated with neurotransmitter release through activation of Gq/11-PLC $[35,36]$. The functional role of striatal M4 receptors is yet to be determined [37].

In our work, there were some differences in the response of MRs in normal and ipsilateral striatum-lesioned rats. Besides the relationship between the effect and the basal spiking activity previous to the activation of MRs, we found that (1) the percent of inhibition evoked by the activation of MRs in normal rats was higher than in lesioned rats and (2) the number of neurons that were inhibited in lesioned rats was lower than in normal rats.

Therefore, our data show the contribution of the striatopallidal pathway to the responses evoked by local activation of MRs in the GP. Supporting this hypothesis, the expression of MRs on GABAergic terminals in many regions of the CNS is common, but the regulation of GABA release by these receptors is more complex; for example, Baba et al. [38] have pointed out that activation of MRs increases GABA release in the substantia gelatinosa of the rat spinal horn; Grillner et al. [39] reported similar results in mesencephalic dopaminergic nuclei, while in the rat subfornical organ, bethanechol blocks GABA release [40]; in a similar manner, it has been found that activation of MRs increases or diminishes GABA release in the chick lateral spiriform nucleus [41].

In our work, the heterogeneous responses evoked by activating local MRs in normal and lesioned rats can be explained according to the differential segregation of M1 and M4 receptors in different pools of striato-pallidal terminals. Differential distribution of MRs in striatal medium spiny neurons is considerable; $100 \%$ of medium spiny enkephalinergic neurons express M1 receptors while $30-50 \%$ of this kind of neurons expresses M4 receptors [23, 25]. M1 receptors diminish GABA release in striatal neurons [34] but the effect of M4 receptors on medium spiny neurons is unknown, although presynaptic activation of M4 receptors in the spinal dorsal horn and in the hippocampus increases GABA release $[42,43]$.

Nevertheless, the differential expression of presynaptic M1 and M4 receptors does not fully explain why in normal rats exists a direct relationship between the baseline spiking rate level and the effect caused by the drugs we tested. There is not an easy explanation of this phenomenon. An idea would be that in pallidal neurons firing at low frequency, the striato-pallidal terminals could express M4 receptors while pallidal neurons with higher spontaneous frequency could express M1 receptors. Segregation of M1 and M4 receptors in striato-pallidal terminals could depend on the basal activity of postsynaptic events. In agreement with this idea, using triple-whole cell patch-clamp recording from GABAergic interneurons in the rat insular cortex, it has been shown that carbachol diminishes or augments the amplitude of inhibitory postsynaptic currents (IPSCs) activating M1 or M4 receptors in different terminals of the same cell. Expression of M1 or M4 depends on the type of postsynaptic neuron [44]; furthermore, three different types of GP neurons have been characterized based on their membrane properties $[45,46]$. However, we concede that single-unit extracellular recordings cannot readily differentiate these types of neurons. In this context, one could not discard the expression of MRs in another afferents, like glutamatergic fibers coming from the subthalamic nucleus that play a major role in globus pallidus activity [47]. Further, activation of M3 receptors modifies the activity of subthalamic neurons [48] but M3 receptors are expressed on afferents fibers and have not been detected in subthalamic neurons [49].

Our results show a tonic cholinergic activity in the GP. It has been shown in preparations similar to ours that neurons of the PPN fire spontaneously $[50,51]$. This spontaneous activity of PPN neurons would explain the presence of the tonic cholinergic release into GP reported here. This cholinergic input could be mediated by MRs as our data on the local blockade of MRs points out. However, we must consider that there are few cholinergic neurons in the medial 
border of the GP near to the basalis nucleus of Meynert and that their contribution to the whole GP activity is unknown [31]. Amacrine cells in the retina corelease GABA and acetylcholine but the stimuli and mechanisms involved are quite complex [52].

Finally, with the destruction of the striato-pallidal fibers, one would expect an increase in the spiking rate of GP neurons of lesioned rats $[53,54]$ but there are no differences between the baseline firing rate recorded in sham rats and that recorded in ipsilateral striatum-lesioned rats; one possible explanation to this is that chloral hydrate as anesthetic modifies the GABAergic transmission as compared to locally anesthetized rats [55]. Despite studies showing the presence of mRNA for M1 and M4 receptors in striato-pallidal neurons, the location of MRs in pallidal neurons should not be disregarded; some of the effects reported here could be due to postsynaptic MRs that until now have not been detected.

\section{Conclusion}

Our data indicate that MRs homogenize the activity of pallidal neurons; neurons with high spiking rates diminish their firing frequency and those with low activity increase it. A similar observation was made in the striatum: activation of MRs in the striatum synchronizes the activity of ensembles of different groups of medium spiny neurons [56]. The effect of MRs on GP neurons depends on their basal activity and on the integrity of the striato-pallidal pathway. Modulation of MRs in the GP could be a pharmacological target to improve some motor system alterations.

\section{References}

[1] R. Katzenschlager, C. Sampaio, J. Costa, and A. Lees, "Anticholinergics for symptomatic management of Parkinson's disease," Cochrane Database of Systematic Reviews, no. 2, Article ID CD003735, 2003.

[2] W. C. Koller, "Pharmacologic treatment of parkinsonian tremor," Archives of Neurology, vol. 43, no. 2, pp. 126-127, 1986.

[3] R. L. Albin, A. B. Young, and J. B. Penney, "The functional anatomy of basal ganglia disorders," Trends in Neurosciences, vol. 12, no. 10, pp. 366-375, 1989.

[4] J. A. Obeso and J. L. Lanciego, "Past, present, and future of the pathophysiological model of the Basal Ganglia," Frontiers in Neuroanatomy, vol. 5, article 39, 2011.

[5] C. D. Blaha and P. Winn, "Modulation of dopamine efflux in the striatum following cholinergic stimulation of the substantia nigra in intact and pedunculopontine tegmental nucleus-lesioned rats," Journal of Neuroscience, vol. 13, no. 3, pp. 1035-1044, 1993.

[6] J. L. Góngora-Alfaro, S. Hernández-López, D. Martínez-Fong, G. Flores, and J. Aceves, "Circling behavior elicited by cholinergic transmission in the substantia nigra pars compacta: involvement of nicotinic and muscarinic receptors," Neuroscience, vol. 71, no. 3, pp. 729-734, 1996.

[7] R. S. Scroggs, C. G. Cardenas, J. A. Whittaker, and S. T. Kitai, "Muscarine reduces calcium-dependent electrical activity in substantia nigra dopaminergic neurons," Journal of Neurophysiology, vol. 86, no. 6, pp. 2966-2972, 2001.

[8] H. Kita, "Physiology of two disynaptic pathways from the sensorimotor cortex to the basal ganglia output nuclei," in
The Basal Ganglia IV: New Ideas and Data on Structure and Function (Advances in Behavioral Biology) Percheron, G. M. McKenzie and J. S. Féger, Eds., pp. 263-276, Plenum Press, New York, NY, USA, 1994.

[9] W. El-Deredy, N. M. Branston, M. Samuel et al., "Firing patterns of pallidal cells in Parkinsonian patients correlate with their pre-pallidotomy clinical scores," NeuroReport, vol. 11, no. 15, pp. 3413-3418, 2000.

[10] G. Heimer, I. Bar-Gad, J. A. Goldberg, and H. Bergman, "Dopamine replacement therapy reverses abnormal synchronization of pallidal neurons in the 1-methyl-4-phenyll-1,2,3,6tetrahydropyridine primate model of parkinsonism," Journal of Neuroscience, vol. 22, no. 18, pp. 7850-7855, 2002.

[11] K. L. Allen, H. J. Waldvogel, M. Glass, and R. L. M. Faull, "Cannabinoid (CB1), GABAA and GABAB receptor subunit changes in the globus pallidus in Huntington's disease," Journal of Chemical Neuroanatomy, vol. 37, no. 4, pp. 266-281, 2009.

[12] H. Nakanishi, N. Hori, and N. Kastuda, "Neostriatal evoked inhibition and effects of dopamine on globus pallidal neurons in rat slice preparations," Brain Research, vol. 358, no. 1-2, pp. 282-286, 1985.

[13] A. Osorio-Espinoza, A. Alatorre, J. Ramos-Jiménez et al., "Presynaptic histamine $\mathrm{H} 3$ receptors modulate glutamatergic transmission in rat globus pallidus," Neuroscience, vol. 176, pp. 20 31, 2011.

[14] E. Querejeta, A. Delgado, R. Valdiosera, D. Erlij, and J. Aceves, "Intrapallidal D2 dopamine receptors control globus pallidus neuron activity in the rat," Neuroscience Letters, vol. 300, no. 2, pp. 79-82, 2001.

[15] T. Shindou, A. Mori, H. Kase, and M. Ichimura, "Adenosine A2A receptor enhances GABAA-mediated IPSCs in the rat globus pallidus," The Journal of Physiology, vol. 532, no. 2, pp. 423-434, 2001.

[16] R. P. Soltis, L. A. Anderson, J. R. Walters, and M. D. Kelland, "A role for non-NMDA excitatory amino acid receptors in regulating the basal activity of rat globus pallidus neurons and their activation by the subthalamic nucleus," Brain Research, vol. 666, no. 1, pp. 21-30, 1994.

[17] A. Charara and A. Parent, "Brainstem dopaminergic, cholinergic and serotoninergic afferents to the pallidum in the squirrel monkey," Brain Research, vol. 640, no. 1-2, pp. 155-170, 1994.

[18] A. I. Gorbachevskaya and O. G. Chivileva, "Organization of the efferent projections of the pedunculopontine tegmental nucleus of the midbrain of the dog pallidum," Neuroscience and Behavioral Physiology, vol. 36, no. 4, pp. 423-428, 2006.

[19] C. B. Saper and A. D. Loewy, "Projections of the pedunculopontine tegmental nucleus in the rat: evidence for additional extrapyramidal circuitry," Brain Research, vol. 252, no. 2, pp. 367-372, 1982.

[20] N. J. Woolf and L. L. Butcher, "Cholinergic systems in the rat brain: III. Projections from the pontomesencephalic tegmentum to the thalamus, tectum, basal ganglia, and basal forebrain," Brain Research Bulletin, vol. 16, no. 5, pp. 603-637, 1986.

[21] M. Piggott, J. Owens, J. O’Brien et al., "Comparative distribution of binding of the muscarinic receptor ligands pirenzepine, AF-DX 384, (R,R)-I-QNB and (R,S)-I-QNB to human brain," Journal of Chemical Neuroanatomy, vol. 24, no. 3, pp. 211-223, 2002.

[22] M. A. Piggott, J. Owens, J. O’Brien et al., "Muscarinic receptors in basal ganglia in dementia with Lewy bodies, Parkinson's disease and Alzheimer's disease," Journal of Chemical Neuroanatomy, vol. 25, no. 3, pp. 161-173, 2003. 
[23] V. Bernard, E. Normand, and B. Bloch, "Phenotypical characterization of the rat striatal neurons expressing muscarinic receptor genes," Journal of Neuroscience, vol. 12, no. 9, pp. 3591-3600, 1992.

[24] M. B. Harrison, M. Tissot, and R. G. Wiley, "Expression of $\mathrm{m} 1$ and $\mathrm{m} 4$ muscarinic receptor mRNA in the striatum following a selective lesion of striatonigral neurons," Brain Research, vol. 734, no. 1-2, pp. 323-326, 1996.

[25] Z. Yan, J. Flores-Hernandez, and D. J. Surmeier, "Coordinated expression of muscarinic receptor messenger RNAs in striatal medium spiny neurons," Neuroscience, vol. 103, no. 4, pp. 1017-1024, 2001.

[26] N. Kayadjanian, A. Menétrey, and M. J. Besson, "Activation of muscarinic receptors stimulates GABA release in the rat globus pallidus," Synapse, vol. 26, no. 2, pp. 131-139, 1997.

[27] G. Paxinos and C. Watson, The Rat Brain in Stereotaxic Coordinates, Academic Press, Amsterdam, The Netherlands, 2007.

[28] Y. Xue, X. H. Han, and L. Chen, "Effects of pharmacological block of $\mathrm{GABA}(\mathrm{A})$ receptors on pallidal neurons in normal and parkinsonian state," Frontiers in Neuroanatomy, vol. 4, article 2, 2010.

[29] E. Soto and R. Vega, "A Turbo Pascal program for on line spike data acquisition and analysis using a standard serial port," Journal of Neuroscience Methods, vol. 19, no. 1, pp. 61-68, 1987.

[30] J. Jakubík, L. Bačáková, E. E. El-Fakahany, and S. Tuček, "Positive cooperativity of acetylcholine and other agonists with allosteric ligands on muscarinic acetylcholine receptors," Molecular Pharmacology, vol. 52, no. 1, pp. 172-179, 1997.

[31] T. Tkatch, G. Baranauskas, and D. J. Surmeier, "Basal forebrain neurons adjacent to the globus pallidus co- express GABAergic and cholinergic marker mRNAs," NeuroReport, vol. 9, no. 9, pp. 1935-1939, 1998.

[32] S. M. Hersch, C. A. Gutekunst, H. D. Rees, C. J. Heilman, and A. I. Levey, "Distribution of m1-m4 muscarinic receptor proteins in the rat striatum: light and electron microscopic immunocytochemistry using subtype-specific antibodies," Journal of Neuroscience, vol. 14, no. 5, pp. 3351-3363, 1994.

[33] M. P. Santiago and L. T. Potter, "Biotinylated m4-toxin demonstrates more M4 muscarinic receptor protein on direct than indirect striatal projection neurons," Brain Research, vol. 894, no. 1, pp. 12-20, 2001.

[34] T. Perez-Rosello, A. Figueroa, H. Salgado et al., "Cholinergic control of firing pattern and neurotransmission in rat neostriatal projection neurons: role of CaV2.1 and CaV2.2 $\mathrm{Ca}^{2+}$ channels," Journal of Neurophysiology, vol. 93, no. 5, pp. 25072519, 2005.

[35] F. Kimura and R. W. Baughman, "Distinct muscarinic receptor subtypes suppress excitatory and inhibitory synaptic responses in cortical neurons," Journal of Neurophysiology, vol. 77, no. 2, pp. 709-716, 1997.

[36] Y. Tan, N. Hori, and D. O. Carpenter, "The mechanism of presynaptic long-term depression mediated by group I metabotropic glutamate receptors," Cellular and Molecular Neurobiology, vol. 23, no. 2, pp. 187-203, 2003.

[37] L. T. Potter, D. D. Flynn, J. S. Liang, and M. H. McCollum, "Studies of muscarinic neurotransmission with antimuscarinic toxins," Progress in Brain Research, vol. 145, pp. 121-128, 2004.

[38] H. Baba, T. Kohno, M. Okamoto, P. A. Goldstein, K. Shimoji, and M. Yoshimura, "Muscarinic facilitation of GABA release in substantia gelatinosa of the rat spinal dorsal horn," The Journal of Physiology, vol. 508, part 1, pp. 83-93, 1998.
[39] P. Grillner, N. Berretta, G. Bernardi, T. H. Svensson, and N. B. Mercuri, "Muscarinic receptors depress GABAergic synaptic transmission in rat midbrain dopamine neurons," Neuroscience, vol. 96, no. 2, pp. 299-307, 2000.

[40] S. H. Xu, E. Honda, K. Ono, and K. Inenaga, "Muscarinic modulation of GABAergic transmission to neurons in the rat subfornical organ," American Journal of Physiology, vol. 280, no. 6, pp. R1657-R1664, 2001.

[41] J. Z. Guo and V. A. Chiappinelli, "Distinct muscarinic receptors enhance spontaneous GABA release and inhibit electrically evoked GABAergic synaptic transmission in the chick lateral spiriform nucleus," Neuroscience, vol. 104, no. 4, pp. 10571066, 2001.

[42] J. C. González, E. Albiñana, P. Baldelli, A. G. García, and J. M. Hernández-Guijo, "Presynaptic muscarinic receptor subtypes involved in the enhancement of spontaneous GABAergic postsynaptic currents in hippocampal neurons," European Journal of Neuroscience, vol. 33, no. 1, pp. 69-81, 2011.

[43] H. M. Zhang, D. P. Li, S. R. Chen, and H. L. Pan, "M2, M3, and M4 receptor subtypes contribute to muscarinic potentiation of GABAergic inputs to spinal dorsal horn neurons," Journal of Pharmacology and Experimental Therapeutics, vol. 313, no. 2, pp. 697-704, 2005.

[44] K. Yamamoto, Y. Koyanagi, N. Koshikawa, and M. Kobayashi, "Postsynaptic cell type-dependent cholinergic regulation of GABAergic synaptic transmission in rat insular cortex," Journal of Neurophysiology, vol. 104, no. 4, pp. 1933-1945, 2010.

[45] A. J. Cooper and I. M. Stanford, "Electrophysiological and morphological characteristics of three subtypes of rat globus pallidus neurone in vitro," The Journal of Physiology, vol. 527, no. 2, pp. 291-304, 2000.

[46] A. Nambu and R. Llinas, "Electrophysiology of globus pallidus neurons in vitro," Journal of Neurophysiology, vol. 72, no. 3, pp. 1127-1139, 1994.

[47] D. Jaeger and H. Kita, "Functional connectivity and integrative properties of globus pallidus neurons," Neuroscience, vol. 198, pp. 44-53.

[48] G. Flores, S. Hernández, M. G. Rosales et al., "M3 muscarinic receptors mediate cholinergic excitation of the spontaneous activity of subthalamic neurons in the rat," Neuroscience Letters, vol. 203, no. 3, pp. 203-206, 1996.

[49] K. Z. Shen and S. W. Johnson, "Presynaptic dopamine D2 and muscarine M3 receptors inhibit excitatory and inhibitory transmission to rat subthalamic neurones in vitro," The Journal of Physiology, vol. 525, no. 2, pp. 331-341, 2000.

[50] M. F. Jeon, Y. Ha, Y. H. Cho, B. H. Lee, Y. G. Park, and J. W. Chang, "Effect of ipsilateral subthalamic nucleus lesioning in a rat parkinsonian model: study of behavior correlated with neuronal activity in the pedunculopontine nucleus," Journal of Neurosurgery, vol. 99, no. 4, pp. 762-767, 2003.

[51] P. Matulewicz, J. Orzeł-Gryglewska, M. J. Hunt, W. Trojniar, and E. Jurkowlaniec, "Hippocampal theta rhythm after serotonergic activation of the pedunculopontine tegmental nucleus in anesthetized rats," Brain Research Bulletin, vol. 83, no. 5, pp. 257-261, 2010.

[52] S. Lee, K. Kim, and Z. J. Zhou, "Role of ACh-GABA cotransmission in detecting image motion and motion direction," Neuron, vol. 68, no. 6, pp. 1159-1172, 2010.

[53] C. S. Chan, R. Shigemoto, J. N. Mercer, and D. J. Surmeier, "HCN2 and HCN1 channels govern the regularity of autonomous pacemaking and synaptic resetting in globus pallidus neurons," Journal of Neuroscience, vol. 24, no. 44, pp. 99219932, 2004. 
[54] J. N. Mercer, C. S. Chan, T. Tkatch, J. Held, and D. J. Surmeier, "Nav1.6 sodium channels are critical to pacemaking and fast spiking in globus pallidus neurons," Journal of Neuroscience, vol. 27, no. 49, pp. 13552-13566, 2007.

[55] H. S. Pan and J. R. Walters, "Unilateral lesion of the nigrostriatal pathway decreases the firing rate and alters the firing pattern of globus pallidus neurons in the rat," Synapse, vol. 2, no. 6, pp. 650-656, 1988.

[56] L. Carrillo-Reid, F. Tecuapetla, O. Ibáñez-Sandoval, A. Hernández-Cruz, E. Galarraga, and J. Bargas, "Activation of the cholinergic system endows compositional properties to striatal cell assemblies," Journal of Neurophysiology, vol. 101, no. 2, pp. 737-749, 2009. 

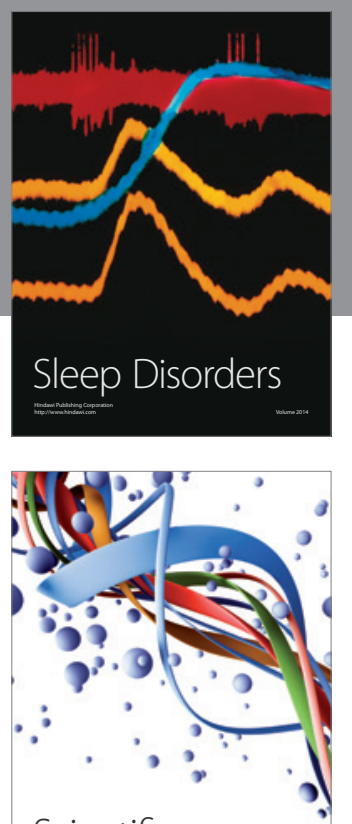

Scientifica
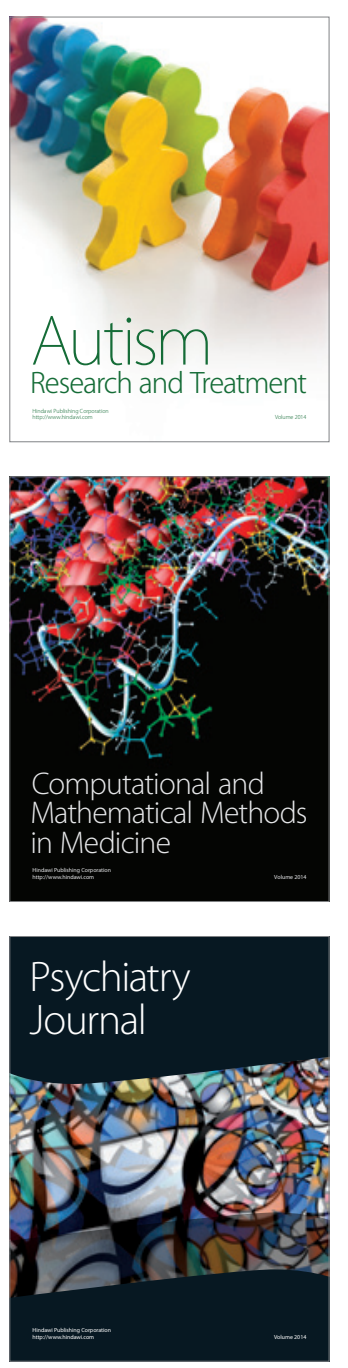
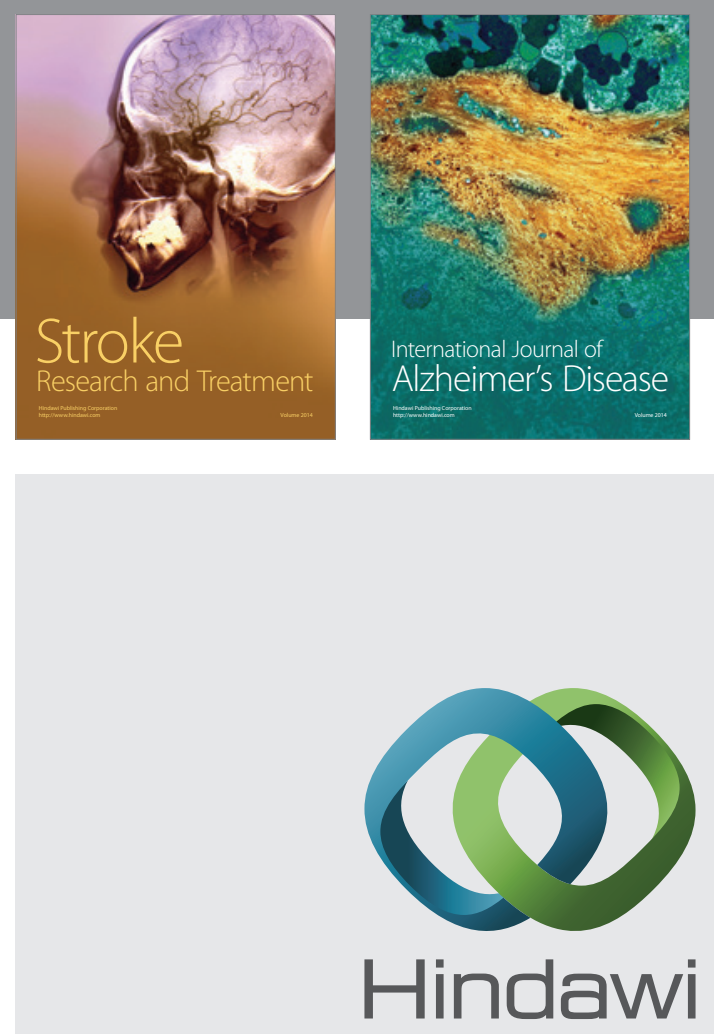

Submit your manuscripts at

http://www.hindawi.com
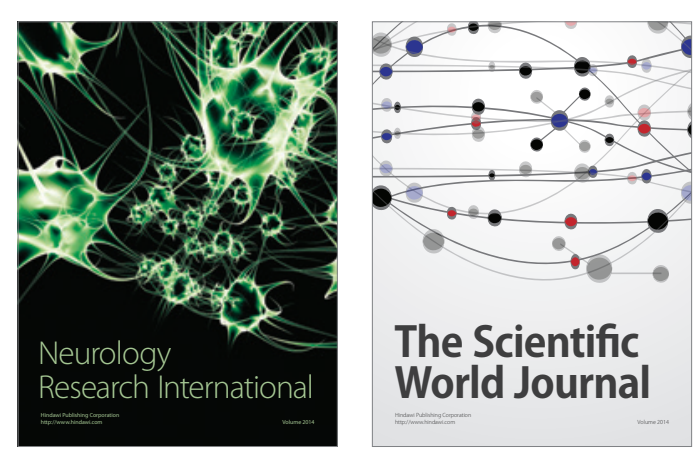

The Scientific World Journal

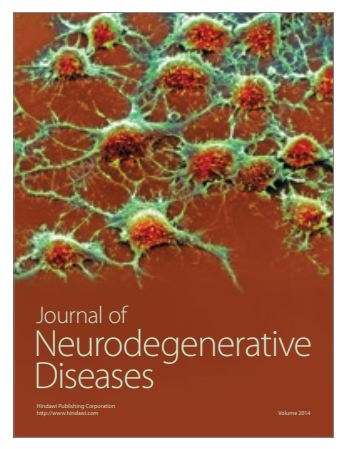

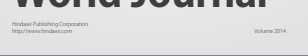

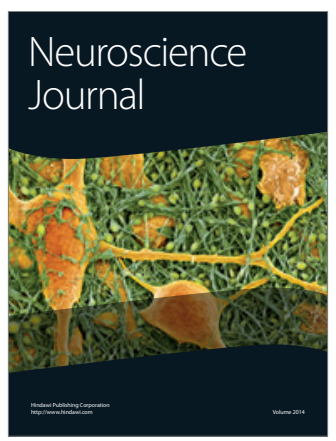

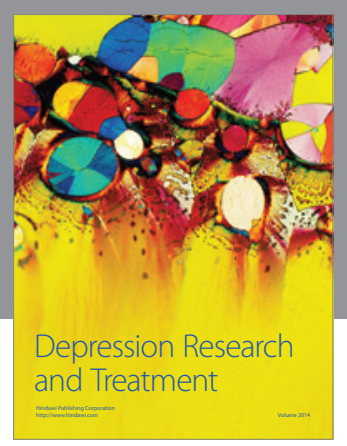
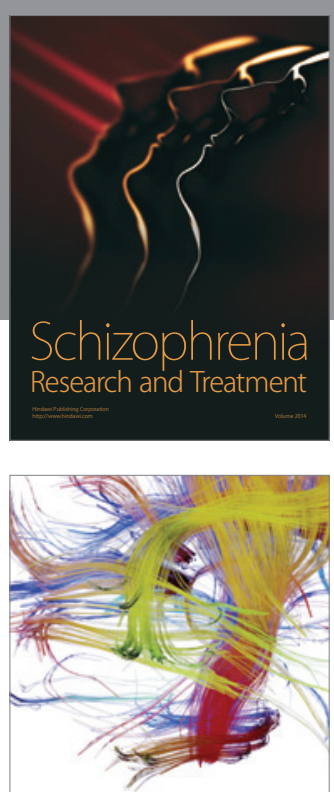

Brain Science

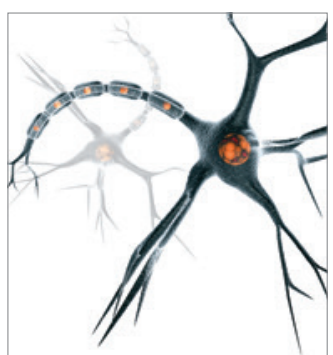

Neural Plasticity
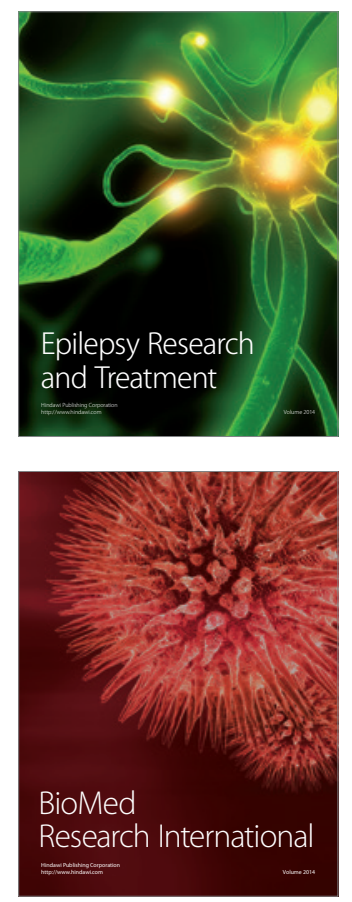

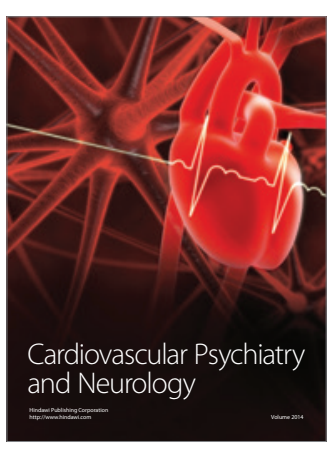

Parkinson's

Disease
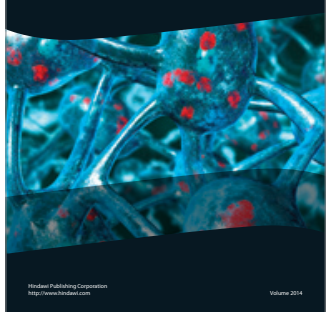